\section{Considering the hypothesis of the pathophysiology of cellulite in its treatment}

\author{
José Maria Pereira de Godoy, ${ }^{1}$ \\ Ana Carolina Pereira de Godoy, ${ }^{2}$ \\ Maria de Fatima Guerreiro Godoy ${ }^{3}$ \\ ${ }^{1}$ Cardiovascular Surgery Department, \\ Medicine School; and FAMERP and \\ CNPq (National Council for Research \\ and Development), São José do Rio \\ Preto, SP; ${ }^{2}$ Faculty of Medical Sciences, \\ Santa Casa de São Paulo; Researcher \\ Group of the Clínica Godoy, São José do \\ Rio Preto, SP; ${ }^{3}$ Occupational Therapist; \\ Medicine School (FAMERP); and \\ Research Godoy Clinic, São José do Rio \\ Preto, SP, Brazil
}

\begin{abstract}
The aim of this study was to evaluate perimetric reductions in the clinical treatment of cellulite (aesthetics) using the Godoy method in a randomized retrospective clinical trial. The medical records of 150 patients treated for cellulite in the period from 2006 to 2011 in the Clinica Godoy were revisited. Treatment comprised manual and mechanical lymph drainage and cervical stimulation for one hour per day over 10 days. The paired t-test was used for statistical analysis, with an alpha error of 5\% (P-value $<0.05)$ being considered acceptable. This study was started after being approved by the Research Ethics Committee of the Medicine School in São José do Rio Preto (FAMERP - no. 3952010), Brazil and after being registered as a clinical trial.

The mean reduction of the 150 patients was $3.81 \pm 2.76 \mathrm{~g}$ (P-value $<0.0001 ; 95 \%$ confidence interval: 3.408-4.223).

A significant reduction in size was seen with the clinical treatment of cellulite giving an improvement in the physical appearance. Pathophysiological mechanisms such as regional skin lymphostasis seem to be involved in the formation of cellulite.
\end{abstract}

\section{Introduction}

Cellulite, characterized by changes in the skin surface relief, is a complex cosmetic problem common to many women. ${ }^{1}$ Cellulite, which appears like orange peel or cottage cheese, with ripples in the skin of the thighs and buttocks, is a complex multifactorial cosmetic disorder of the layer of subcutaneous fat and the overlying skin sur- face. ${ }^{2}$ Although the extracellular matrix and lymphatic system disorders can enhance its appearance, cellulite results essentially from an excessive storage of fat in adipose tissue, which exerts considerable pressure on the surrounding tissue of the skin and creates an appearance of irregular dimples. ${ }^{3}$

Recent studies suggest that changes in the lymphatic system and the production of substances within the interstitial space may be the physiopathological cause of cellulite. As a result, regional skin lymphostasis leads to their accumulation as this aggravates the mobilization of these substances. ${ }^{4-6}$ Another study evaluating 25 gene polymorphisms associated with aesthetic cellulite identified two, the ACE (rs1799752) and HIF1A (rs11549465) genes as having significant correlations. $^{7}$ However, therapies used to treat cellulite do not always deal with the pathophysiology of the disease. The aim of this study was to retrospectively evaluate the clinical outcomes of patients with cellulite treated using the Godoy concept and technique.

\section{Materials and Methods}

The medical records of 150 patients treated for cellulite from the total treated in the Clinica Godoy between 2006 and 2011 were randomly selected by lottery for this quantitative retrospective study.

Routine evaluations included an investigation of the patient's history, physical examination, perimetry and photography before and after treatment. The three largest differences in diameters along the legs were considered. Patients with cyclic edema were treated before starting treatment for cellulite and patients with a body mass index greater than 30 (obese) were excluded.

Treatment was based on manual lymph drainage with one session per day for 10 days using the technique developed by the author. This technique is characterized by movements that compress and subsequently slide along the route of the lymphatic vessels, in particular the great saphenous lymphatic chain, up to the corresponding lymph nodes. Fifteen minutes per day of cervical stimulation. was associated to this as was one hour per day of mechanical lymph drainage using the RAGodoy ${ }^{\circledR}$ device. ${ }^{8}$ The paired t-test was used for statistical analysis, with an alpha error of 5\% (P-value $<0.05)$ being considered acceptable. This study was started after being approved by the Research Ethics Committee of the Medicine School in São José do Rio Preto (FAMERP) and being registered as a clinical trial.
Correspondence: José Maria Pereira de Godoy, Cardiovascular Surgery Department, Medicine School; and FAMERP and CNPq (National Council for Research and Development), Avenida Constituição, 1306 São José do Rio Preto-SP, Cep: 15025-120, Brazil.

E-mail: godoyjmp@gmail.com

Key words: Cellulite; Godoy method; evaluation.

Received for publication: 12 August 2017. Accepted for publication: 5 September 2017.

This work is licensed under a Creative Commons Attribution-NonCommercial 4.0 International License (CC BY-NC 4.0).

(C) Copyright J.M. Pereira de Godoy et al., 2017 Licensee PAGEPress, Italy

Dermatology Reports 2017; 9:7352

doi:10.4081/dr.2017.7352

\section{Results}

The mean age of participants was 34.49 years with a minimum age of 18 years and a maximum of 58 years. A significant mean reduction of $3.81 \pm 2.76$ grams ( $\mathrm{P}$-value $<0.0001$; 95\% CI: 3.408-4.223) was detected. Figure 1 shows the perimeters before and after treatment and the mean reduction.

\section{Discussion}

The current study used lymph drainage in the treatment of aesthetic cellulite to reduce the perimetry of the leg and thus improve the aesthetic appearance. One-hour sessions of lymph drainage were performed for 10 days over two weeks.

The authors believe that the cause of cellulite is changes in the lymphatic system and the production of substances within the interstitial space with the consequence the regional cutaneous lymphostasis. Thus, the advantage of this approach is that it directly interferes in the pathophysiology of cellulite. The hypothesis of the authors is that stimulation of this system relocates macromolecules in the interstitial space to the circulation. Thus the macromolecules are redistributed around the body. This hypothesis is supported as intensive treatment for four hours per day cause reductions of between 6 to $10 \mathrm{~cm}$ in the perimeters of the legs but without changing the body weight. ${ }^{4-6}$ The patients selected for intensive treatment were not obese and did not have lipedema and edema. However, in the clinical practice it is common to see an associa- 
tion of obesity, edema, lymphedema and lipedema with cellulite. This fact raises doubts about the pathophysiology of different diseases. Obesity is an aggravating factor for lipedema, lymphedema and even for cellulite.

Patients with lymphedema associated with cellulite who treat the lymphedema using manual lymph drainage, compression therapy and mechanical lymph drainage using the RAGodoy device, in addition to the reduction in lymphedema have improvements in the cellulite. Obese patients who lose weight have reduced perimetric measurements similar to in the treatment of cellulite.

In this study the mean perimetric reduction of cellulite was around 0.2 to $0.3 \mathrm{~cm}$ per hour. However, the result is time- and technique-dependent with the evaluations being made after 10 sessions.

The main improvements in our knowledge over the last few years are the hypothesis of the pathophysiology of cellulite, which has since been clinically proven ${ }^{4-6}$ and its genetic association. ${ }^{7}$ All diseases have a pathophysiology and treatment should interfere in this physiopathology. The identification of genetic changes suggests that cellulite is a disease, even though it is common to most women.

The therapeutic proposal to stimulate the lymphatic system, based on the assumption of regional cutaneous lymphostasis, ${ }^{4}$ is a symptomatic approach as genetic changes have been detected. However, at the moment we believe this approach with clinical principles appropriate. However, comorbidities such as edema and obesity are key to achieving the expected results in the changes that led to regional deposits. One of these associations is idiopathic cyclic edema, a common disease in patients with much edematous cellulite, where control is essential in order to have a good result in the treatment of cellulite.

With this technique the reduction of cellulite is maintained for years (at least five) as long as the body weight is controlled and the individual does not have edema or lipedema. The swelling in patients with idiopathic cyclic edema must be controlled over the long term to prevent relapse.

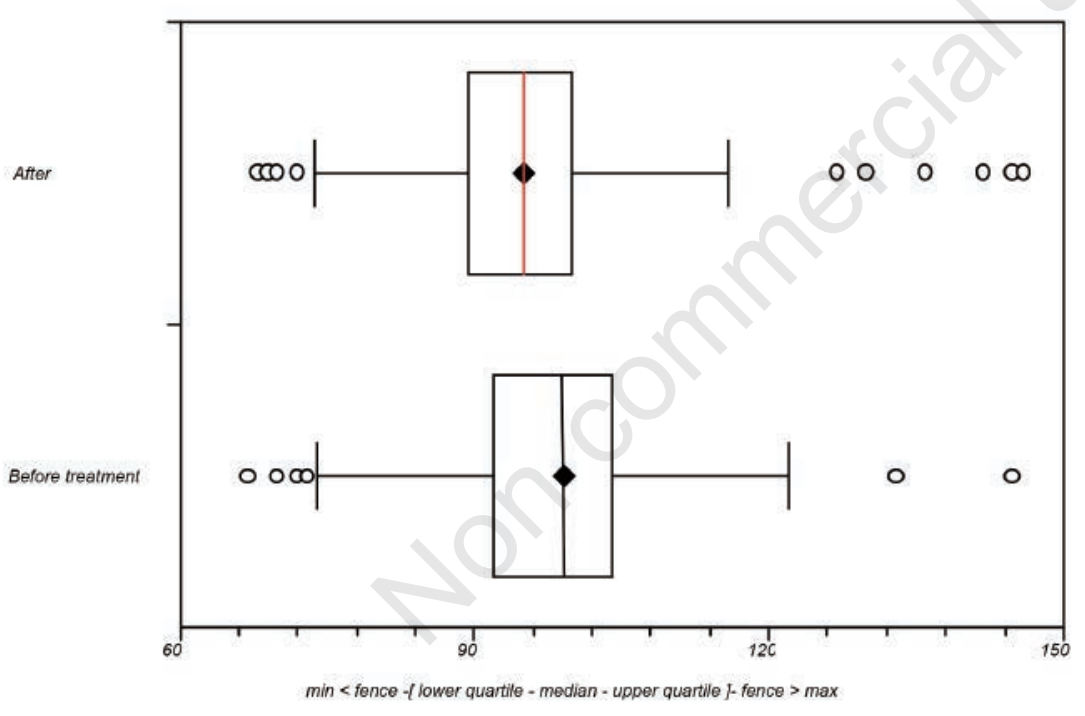

Figure 1. Box and whisker plot of the reduction in perimetry comparing before and after treatment for cellulite.

\section{Conclusions}

By interfering in the pathophysiological mechanisms of cellulite such as regional cutaneous lymphostasis, satisfactory clinical results can be achieved in the treatment of cellulite.

\section{References}

1. Terranova F, Berardesca E, Maibach H. Cellulite: nature and aetiopathogenesis. Int J Cosmet Sci 2006;28:157-67.

2. Emanuele E, Minoretti P, Altabas K, et al. Adiponectin expression in subcutaneous adipose tissue is reduced in women with cellulite. Int $\mathrm{J}$ Dermatol 2011;50:412-6.

3. Vogelgesang B, Bonnet I, Godard N, et al. In vitro and in vivo efficacy of sulfo-carrabiose, a sugar-based cosmetic ingredient with anti-cellulite properties. Int $\mathrm{J}$ Cosmet Sci 2011;33:120-5.

4. de Godoy JM, de Godoy Mde F. Physiopathological hypothesis of cellulite. Open Cardiovasc Med J 2009;31:96-7.

5. Godoy JMP, Almeida EMMZNM, Silva SH, Godoy MFG. Pilot study of the intensive treatment of cellulitis. RBM Especial Clínica Geral 2010;67:30-2.

6. de Godoy JM, Groggia MY, Ferro Laks L, Guerreiro de Godoy Mde F. Intensive treatment of cellulite based on physiopathological principles. Dermatol Res Pract 2012;2012: 834280 .

7. Emanuele E, Bertona M, Geroldi D. A multilocus candidate approach identifies ACE and HIF1A as susceptibility genes for cellulite. $\mathrm{J}$ Eur Acad Dermatol Venereol 2010;24:930-5.

8. de Godoy JM, de Godoy Mde F. Evaluation of the prevalence of concomitant idiopathic cyclic edema and cellulite. Int J Med Sci 2011;8:453-5. 